\title{
Expression of tumor suppressor programmed cell death 4 in endometrioid endometrial carcinomas and clinicopathological significance
}

\author{
YANPING LIU ${ }^{1 *}$, HAN SUN $^{2,3 *}$, HONGJU MAO ${ }^{4}$, MENG GAO $^{2}$, XIAO TAN $^{5}$, YUE $^{2}{ }^{2}$, YAN LI $^{2}$, \\ GUY MUTANGALA MULOYE ${ }^{1}$, LINING ZHANG ${ }^{2}$, XIAOYAN WANG $^{2}$ and ZENGTAO WEI ${ }^{1,6}$
}

\begin{abstract}
Departments of ${ }^{1}$ Gynecology and Obstetrics and ${ }^{2}$ Immunology, Shandong University School of Medicine, Jinan, Shandong 250012; ${ }^{3}$ Department of Clinical Laboratory Services, Linyi People's Hospital, Linyi, Shandong 276000;

${ }^{4}$ Department of Infection, Jinan Central Hospital Affiliated to Shandong University, Jinan, Shandong 250013;

${ }^{5}$ Department of Pathology, The People's Hospital of Linyi City, Linyi, Shandong 276000; ${ }^{6}$ Department of Gynecology and Obstetrics, Jinan Central Hospital Affiliated to Shandong University, Jinan, Shandong 250013, P.R. China
\end{abstract}

Received October 22, 2015; Accepted March 30, 2017

DOI: $10.3892 / \mathrm{ol} .2018 .8517$

\begin{abstract}
Programmed cell death 4 (PDCD4), as a novel tumor suppressor, serves important roles in the pathogenesis of tumors. The expression of PDCD4 is downregulated or lost in various human tumors. However, the expression of PDCD4 in endometrial cancer and the clinicopathological significance remain unclear. The aim of the present study was to investigate the expression of PDCD4 in endometrioid endometrial carcinoma (EEC) and the association with clinicopathological parameters. The expression of PDCD4 in EEC tissues and control endometrium was detected by reverse transcription-quantitative polymerase chain reaction, western blotting and immunohistochemistry. PDCD4 expression was also investigated in control endometrial glandular epithelial cells and the endometrial cancer KLE cell line by immunocytochemistry, and the association between PDCD4 expression and clinicopathological parameters of patients with EEC was analyzed. The results demonstrated that PDCD4-positive staining was mainly located in the cytoplasm of endometrial glandular epithelial cells and EEC cells. The staining index of PDCD4 in the proliferative phase was significantly increased
\end{abstract}

Correspondence to: Dr Zengtao Wei, Department of Gynecology and Obstetrics, Jinan Central Hospital Affiliated to Shandong University, 105 Jiefang Road, Jinan, Shandong 250013, P.R. China

E-mail: weizengtao1970@163.com

Dr Xiaoyan Wang, Department of Immunology, Shandong University School of Medicine, 44 Wenhua Xi Road, Jinan, Shandong 250012, P.R. China

E-mail:wxy990809@163.com

*Contributed equally

Key words: programmed cell death 4, tumor suppressor gene, endometrial cancer, tumor grade compared with that in the secretory phase of control endometrium $(\mathrm{P}<0.001)$. There was significantly decreased PDCD4 expression in grade $(G) 2 / 3$ EEC tissues compared with the proliferative phase of control endometrium $(\mathrm{P}<0.001)$. PDCD4 expression was significantly associated with tumor grade. The PDCD4 levels in G1 EEC tissues were higher compared with the $\mathrm{G} 2 / 3$ EEC group $(\mathrm{P}<0.01)$. The results indicated that PDCD4 is associated with the histological grade of EEC, and that PDCD4 may be a valuable indicator of the degree of tumor malignancy in patients with EEC.

\section{Introduction}

Endometrial cancer (EC) is the fourth most common cancer in females, behind breast, colorectal and lung cancer (1). EC can be classified into type I and type II based on etiology, clinical behavior and pathological characteristics (2). Type I is estrogen-dependent endometrioid endometrial carcinoma (EEC), while type II is non-EEC (2). EECs account for $70-80 \%$ of ECs, and are associated with unopposed estrogen stimulation (2). EC is often diagnosed in its early stages due to early clinical signs, including abnormal uterine bleeding and vaginal discharge (3). For patients in early stage EC, surgery is the best choice of treatment and the 5-year survival rate is $\sim 96 \%$ (3). However, a number of patients with advanced stage EC develop abdominal or pelvic pain, abdominal distension, early satiety or change in bowel or bladder function, and the survival rate markedly decreases (3). Although these patients in advanced stages are traditionally treated using chemotherapy, radiotherapy and hormonal therapy, there are still numerous patients who are less sensitive to present therapy. Therefore, the identification of novel molecular biomarkers may be helpful for the early diagnosis and treatment of patients with EC.

Programmed cell death 4 (PDCD4) was first identified as a gene upregulated following initiation of apoptosis (4). Subsequently, it has been identified as a novel tumor suppressor gene that performs an important role in inhibiting 
tumorigenesis and tumor progression at the transcriptional and translational levels $(5,6)$. Several studies have demonstrated that PDCD4 affects the transcription of specific genes by modulating the activities of certain transcription factors, including c-Jun (7), Sp1 and p53 $(8,9)$. PDCD4 suppresses protein translation in two different ways: The eIF4A-dependent mechanism (PDCD4 interacts with the eukaryotic translation initiation factor eIF4A to inhibit the RNA helicase activity of eIF4A) (10), and the eIF4A-independent mechanism [PDCD4 directly interacts with poly (A)-binding protein through the RNA binding domains and regulates protein translation] (11). PDCD4 is expressed ubiquitously in normal tissues, including liver (12), kidney and brain $(13,14)$, but downregulated or lost in various human tumors, including lung (15), colorectal (16), breast and ovarian cancers $(17,18)$. However, the expression of PDCD4 in patients with EEC and the clinicopathological significance remain unclear.

The present study aimed to detect the expression status of PDCD4 in EEC, the most common type of EC (2), and analyze the association between PDCD4 expression and clinicopathological parameters of patients with EEC.

\section{Materials and methods}

Samples collection. A total of 15 frozen, fresh EEC tissues and 52 formalin-fixed, paraffin-embedded EEC specimens, as well as 18 frozen, fresh control endometrium and 70 formalin-fixed, paraffin-embedded control specimens (including in the 36 proliferative phase and 34 from the secretory phase) were obtained from The Department of Gynecology and Obstetrics, Jinan Central Hospital affiliated to Shandong University (Shandong, China) between February 2012 and December 2015. A total of 67 patients with EEC, with mean age of 56.2, were confirmed by histological examination of biopsies obtained during surgery. None of the patients had received neoadjuvant chemotherapy or hormone treatment prior to the operation. Endometrial tissues were categorized as proliferative or secretory according to the patient's menstrual history, which was confirmed by histopathological examination. All slides were evaluated by two gynecological pathologists to confirm the histological type, International Federation of Gynecology and Obstetrics (FIGO) stage, the histological grade, the depth of myometrial invasion and the estrogen receptor (ER) and progesterone receptor (PR) expression status. FIGO stage and histological grade were evaluated as described in previous reports $(19,20)$. The ER and PR staining was performed and evaluated as described previously (21). The above clinicopathological parameters of patients with EEC were obtained from Jinan Central Hospital affiliated to Shandong University and outlined in Table I. The present study was approved by the Institutional Ethics Committee of Shandong University and all patients provided written, informed consent.

Reverse transcription-quantitative polymerase chain reaction (RT-qPCR). TRIzol reagent (Tiangen Biotech Co., Ltd., Beijing, China) was used to isolate total RNA of frozen fresh EEC tissues and control endometrium. RNA was reverse transcribed to cDNA with the FastQuant RT kit (Tiangen Biotech Co., Ltd.) according to the manufacturer's protocol. RT-qPCR was used to detect the mRNA expression of PDCD4 in reaction mixture containing cDNA, UltraSYBR Mixture (CWBIO, Beijing, China) and specific primers using a Bio-Rad CFX96 real-time PCR instrument (Bio-Rad Laboratories, Inc., Hercules, CA, USA). The PDCD4 primers were: forward, 5'-ACAGGTGTATGATGTGGAGGA-3' and reverse, 5'-TTC TCAAATGCCAGTCTTTCATCCAA-3'. GAPDH was used as an internal control. The specific primers for GAPDH were: forward, 5'-AACGGATTTGGTCGTATTGGG-3' and reverse, 5'-CCTGGAAGATGGTGATGGGAT-3'. The reaction mixture was denatured at $95^{\circ} \mathrm{C}$ for $10 \mathrm{~min}$, followed by 39 cycles of $95^{\circ} \mathrm{C}$ for $15 \mathrm{sec}, 60^{\circ} \mathrm{C}$ for $1 \mathrm{~min}$ and $65^{\circ} \mathrm{C}$ for $5 \mathrm{sec}$ to stop the reaction. Each sample was performed in triplicate and the $2^{-\Delta \Delta \mathrm{Cq}}$ method (22) was used to analyze the results.

Western blotting. Frozen, fresh EEC and control endometrium specimens were ground mechanically, and total protein was extracted using radioimmunoprecipitation assay buffer containing $1 \%$ phenylmethanesulfonyl fluoride and $0.5 \%$ phosphatase inhibitor (Thermo Fisher Scientific, Inc., Waltham, MA, USA). Following centrifugation at $12,000 \mathrm{x}$ g for $30 \mathrm{~min}$ at $4^{\circ} \mathrm{C}$, the protein concentration of supernatant was measured with a bicinchoninic acid kit (Thermo Fisher Scientific, Inc.) according to the manufacturer's protocol. Protein $(30 \mu \mathrm{g}$ per sample) was separated with $10 \%$ SDS-PAGE and transferred to a polyvinylidene fluoride membrane. The membrane was blocked with $5 \%$ bovine serum albumin (Gibco; Thermo Fisher Scientific, Inc.) and incubated with a rabbit anti-human PDCD4 monoclonal antibody (dilution, 1:1,000; cat. no., 9535; Cell Signaling Technology, Inc. Danvers, MA, USA) and a rabbit anti-human $\beta$-actin polyclonal antibody (dilution, 1:1,000; cat. no., 20536-1-AP; Proteintech, Wuhan, China) at $4^{\circ} \mathrm{C}$ overnight. Following 3 washes with phosphate-buffered saline, the membrane was incubated with goat anti-rabbit IgG conjugated with horseradish peroxidase (HRP; dilution, 1:2,000; cat. no., ZB-2301, ZSJQB Co. Ltd., Beijing, China) for $1 \mathrm{~h}$ at room temperature. The protein bands were detected using the enhanced chemiluminescence method with the reagents immobilon western chemilum HRP substrate solution (cat. nos., 16267A4; EMD Millipore, Billerica, MA, USA) and immobilon western chemilum HRP substrate Luminol Peroxide solution (cat. nos., 16267B4; EMD Millipore), according to the manufacturer's protocol.

Immunohistochemistry (IHC). The $4-\mu \mathrm{m}$ sections from $4 \%$ formalin-fixed, paraffin-embedded EEC specimens and control endometrium were deparaffinized and rehydrated with an ethanol gradient $(100,100,95,85,70$ and 60\%), and then antigen retrieval was performed by microwave heating. The slides were blocked using $3 \% \mathrm{H}_{2} \mathrm{O}_{2}$, and $10 \%$ normal goat serum (Beijing Dingguo Changsheng Biotechology Co., Ltd., Beijing, China) for $15 \mathrm{~min}$ at $37^{\circ} \mathrm{C}$ was used to block non-specific binding. The sections were then incubated with a rabbit anti-human PDCD4 monoclonal antibody (dilution, 1:100; cat. no., 9535; Cell Signaling Technology, Inc.) overnight in a wet chamber at $4^{\circ} \mathrm{C}$. The slides were incubated for $30 \mathrm{~min}$ at $37^{\circ} \mathrm{C}$ with HRP-conjugated goat anti-rabbit IgG (dilution, 1:100; cat. no., ZB-2301; ZSJQB Co., Ltd.), and visualized using a diaminobenzidine (DAB) kit (ZSJQB Co., Ltd.) according to the manufacturer's protocol, followed by counterstaining with hematoxylin. 
Table I. Associations of PDCD4 expression with clinicopathological parameters in endometrioid endometrial carcinoma.

\begin{tabular}{|c|c|c|c|c|}
\hline \multirow[b]{2}{*}{ Parameters } & \multicolumn{3}{|c|}{ PDCD4 expression } & \multirow[b]{2}{*}{ P-value $\left(\chi^{2}\right.$ test } \\
\hline & Total patients, $\mathrm{n}$ & Negative-weak, n (\%) & Moderate-strong, n (\%) & \\
\hline \multicolumn{5}{|l|}{ Age } \\
\hline$\leq 55$ years & 20 & $9(45)$ & $11(55)$ & 0.0637 \\
\hline$>55$ years & 31 & $22(71)$ & $9(29)$ & \\
\hline \multicolumn{5}{|c|}{ Myometrial invasion } \\
\hline$\leq 50 \%$ & 32 & $17(53)$ & $15(47)$ & 0.146 \\
\hline$>50 \%$ & 19 & $14(74)$ & $5(26)$ & \\
\hline \multicolumn{5}{|l|}{ FIGO stage } \\
\hline IA & 33 & $19(59)$ & $14(41)$ & 0.5251 \\
\hline IB-III & 18 & $12(67)$ & $6(33)$ & \\
\hline \multicolumn{5}{|l|}{ Histological grade } \\
\hline Grade 1 & 14 & $3(21)$ & $11(79)$ & 0.0013 \\
\hline Grade $2 / 3$ & 38 & $27(71)$ & $11(29)$ & \\
\hline \multicolumn{5}{|l|}{ Estrogen receptor } \\
\hline Negative-weak & 12 & $5(42)$ & $7(58)$ & 0.1167 \\
\hline Moderate-strong & 31 & $21(68)$ & $10(32)$ & \\
\hline \multicolumn{5}{|c|}{ Progesterone receptor } \\
\hline Negative-weak & 12 & $7(58)$ & $5(42)$ & 0.7957 \\
\hline Moderate-strong & 37 & $20(54)$ & $17(46)$ & \\
\hline
\end{tabular}

PDCD4, programmed cell death 4; FIGO, the International Federation of Gynecology and Obstetrics.

The results of IHC staining were scored by evaluating the extent and intensity of staining in 5 fields of view using light microscopy (Olympus Co. Tokyo, Japan) at x100, x200 and x400 magnification, using a previously described immunoreactive scoring method (23). The staining intensity was divided into four grades: -, score $0 ;+$, score $1 ;++$, score 2 ; and +++ , score 3 . The positive expression area was also classified into four categories:,$-<1 \%$, score $0 ;+, 1-33 \%$, score $1 ;++, 34-66 \%$, score 2 ; and,$+++ 67-100 \%$, score 3 . The sum of intensity and area scores was used as the final PDCD4 staining score. The expression of PDCD4 was defined as follows: No expression, total score 0; weak expression, total score 1 and 2; moderate expression, total score 3 and 4; strong expression, total score 5 and 6 . All slides were scored by two independent pathologists who were blind to the clinical data of patients. When there were discrepancies between two pathologists, the mean score was used.

Isolation and culture of endometrial glandular epithelial and stromal cells. Methods for the isolation and culture of endometrial cells were based on methods in previously published reports (24). Briefly, secretory phase control endometrium samples were extracted from the previously described patients. The samples were placed immediately in a mixture of Dulbecco's modified Eagle's medium/F12 (1:1) supplemented with $100 \mathrm{U} / \mathrm{ml}$ of penicillin and $100 \mathrm{U} / \mathrm{ml}$ of streptomycin (all HyClone; GE Healthcare Life Sciences, Logan, UT, USA). The tissues were then minced into small pieces and digested with $0.25 \%$ collagenase type IA (Sigma-Aldrich; Merck KgaA,
Darmstadt, Germany) in an agitating water bath for $50 \mathrm{~min}$ at $37^{\circ} \mathrm{C}$. The pre-warmed DMEM/F12 medium containing $10 \%$ fetal bovine serum (Gibco; Thermo Fisher Scientific, Inc.) was used to stop the collagenase activity. The cell suspension was firstly filtered through a $154-\mathrm{mm}$ monofilament nylon mesh and then a $38.5-\mathrm{mm}$ monofilament nylon mesh. To obtain stromal cells, the cell suspension was collected and centrifuged at $800 \mathrm{x} \mathrm{g}$ for $10 \mathrm{~min}$ at room temperature, the pellet was resuspended in medium and incubated in 24-well plates with coverslips for $2 \mathrm{~h}$ at $37^{\circ} \mathrm{C}$ in $95 \%$ air and $5 \% \mathrm{CO}_{2}$. The medium was then replaced with fresh medium in order to purify the stromal cells. To obtain glandular epithelial cells, the 38.5-mm monofilament was washed thoroughly upside down with medium. The medium was collected and centrifuged at $800 \mathrm{x} g$ for $10 \mathrm{~min}$ at room temperature, the pellet was resuspended in medium and incubated in 24-well plates with coverslips at $37^{\circ} \mathrm{C}$ in $5 \% \mathrm{CO}_{2}$. The cultured endometrial glandular epithelial cells and stromal cells were characterized by immunocytochemistry (ICC) with mouse anti-human vimentin and cytokeratin antibodies (ZSJQB Co., Ltd. Beijing, China).

ICC. KLE cells (G3 endometrioid endometrial carcinoma cells) were purchased from China Center for Type Culture Collection (Wuhan, China). The isolated glandular epithelial, stromal and KLE cells were cultured at $37^{\circ} \mathrm{C}$ overnight in 24-well plates with coverslips and used for the following ICC analysis. The cells on coverslips were fixed with $4 \%$ paraformaldehyde for $30 \mathrm{~min}$ at room temperature, and then blocked with $0.3 \% \mathrm{H}_{2} \mathrm{O}_{2}$ for $10 \mathrm{~min}$ at room temperature. The coverslips 
were incubated with rabbit anti-human PDCD4 (dilution, 1:100; cat. no., 9535; Cell Signaling Technology, Inc.), mouse anti-human vimentin (dilution, 1:100; cat. no., ZM-0260) and anti-cytokeratin (dilution, 1:100; cat. no., ZM-0071; both ZSJQB Co., Ltd.) antibodies for $2 \mathrm{~h}$ at $37^{\circ} \mathrm{C}$. The coverslips were then incubated with a HRP-conjugated goat anti-rabbit secondary antibody (dilution, 1:100; cat. no., ZB-2301; ZSJQB Co., Ltd.) and HRP-conjugated goat anti-mouse secondary antibody (dilution, 1:100; cat. no., ZB-2305; ZSJQB Co., Ltd.), and then visualized using the aforementioned DAB kit according to the manufacturer's protocol, followed by counterstaining with hematoxylin. The slides were observed under a light microscope (Olympus Corporation, Tokyo, Japan) with x400 magnification.

Statistical analysis. Unpaired t-tests were performed to analyze the results of RT-qPCR, and the data are presented as the mean \pm standard error of mean. The comparison of PDCD4 protein expression between the EEC group and the control group was assessed using a Mann-Whitney test; the result was reported as the median. The $\chi^{2}$ test was used to analyze the data of immunohistochemical staining and the association of PDCD4 protein expression with clinicopathological parameters. GraphPadPrism 5 (GraphPad Software, Inc., La Jolla, CA, USA) was used for statistical analysis. $\mathrm{P}<0.05$ was considered to indicate a statistically significant difference.

\section{Results}

Expression of PDCD4 $m R N A$ and protein in the EEC samples and control endometrium detected by RT-qPCR and western blotting. To evaluate the expression levels of PDCD4 in EEC tissues, frozen fresh EEC samples and control endometrium were firstly collected, and PDCD4 mRNA expression was detected by RT-qPCR. As shown in Fig. 1, there was no significant difference in PDCD4 mRNA between the control and EEC group $(\mathrm{P}=0.88)$. The expression of $\mathrm{PDCD} 4$ protein in these samples was then detected by western blotting. The data demonstrated that, in the patients with EEC, PDCD4 protein expression remained the same as the control $(\mathrm{P}=0.10$; Fig. 2), which is consistent with the findings of RT-qPCR.

Expression of PDCD4 protein in the EEC samples and control endometrium detected by IHC staining. To confirm the location and levels of PDCD4 protein in the EEC tissues and control endometrium, formalin-fixed, paraffin-embedded EEC samples and control endometrium were recruited, and the expression of PDCD4 was detected by IHC.

The results showed that PDCD4 positive staining was mainly located in the cytoplasm of endometrial glandular epithelial cells, but no immunoreactivity of PDCD4 was observed in endometrial stromal cells (Fig. 3A and B). To explore whether the expression of PDCD4 is affected by ovarian steroid, differences in PDCD4 expression were compared between proliferative and secretory phase control endometrium, and it was found that the staining index of PDCD4 in the proliferative phase $(n=36)$ was significantly increased compared with that in the secretory phase $(n=34)$ of control endometrium $(\mathrm{P}<0.001$; Fig. $3 \mathrm{~A}$ and $\mathrm{B})$.

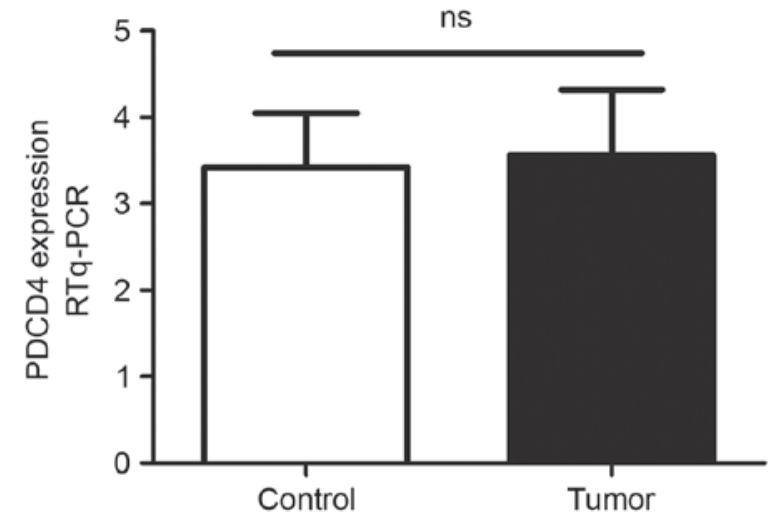

Figure 1. Expression levels of PDCD4 mRNA in the EEC and control groups. The PDCD4 mRNA levels in 15 EEC tissues and 18 control endometrium were determined by RT-qPCR. Data were normalized to GAPDH. No significant difference in PDCD4 mRNA expression was observed between the EEC and control groups $(\mathrm{P}=0.88)$. PDCD4, programmed cel death 4; EEC, endometrioid endometrial carcinomas; ns, no significance; RT-qPCR, reverse transcription-quantitative polymerase chain reaction.

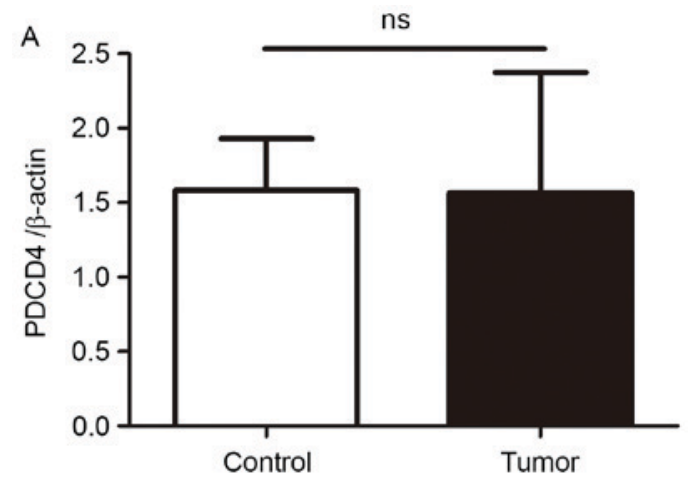

B

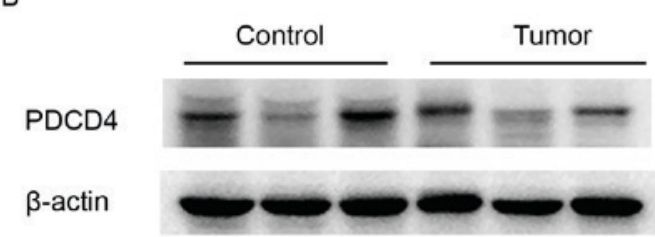

Figure 2. Expression levels of PDCD4 protein in the EEC and control groups. The PDCD4 protein levels in 15 EEC tissues and 18 control endometrium were detected by western blotting. $\beta$-actin was used as a loading control to assure equal amounts of protein in all lanes. (A) The statistical analysis of PDCD4 protein in 15 EEC tissues and 18 control endometrium. (B) The representative images of western blot analysis of PDCD4 in EEC tissues and control endometrium. The results of western blot analysis showed that PDCD4 protein expression remained the same in the EEC group compared with the control group. PDCD4, programmed cell death 4; EEC, endometrioid endometrial carcinomas; ns, no significance.

In the EEC samples, PDCD4 staining was also mainly present in the cytoplasm of EEC cells (Fig. 3C-E). Furthermore, there was significantly decreased PDCD4 expression in grade (G) 2/3 EEC tissues compared with the proliferative phase of control endometrium ( $\mathrm{P}<0.001$; Fig. 4). Additionally, the PDCD4 expression in G1 EEC samples was increased compared with the secretory phase of control endometrium. However, no statistically significant difference in PDCD4 staining was observed between the proliferative phase of 
A

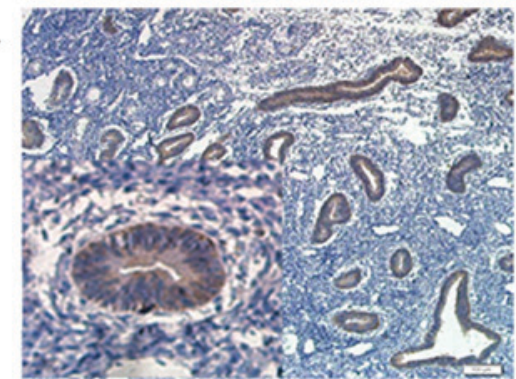

c

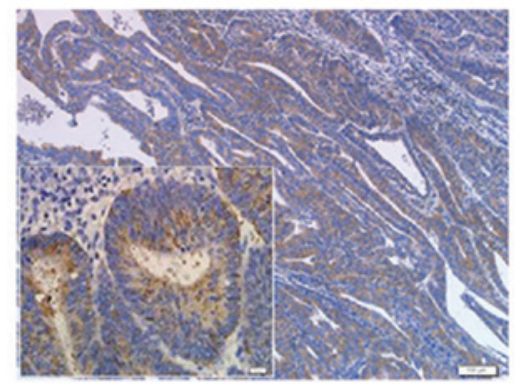

E

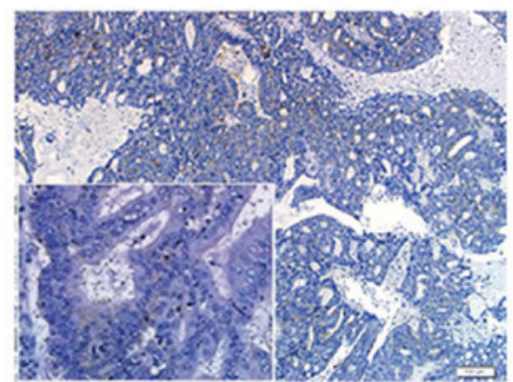

B
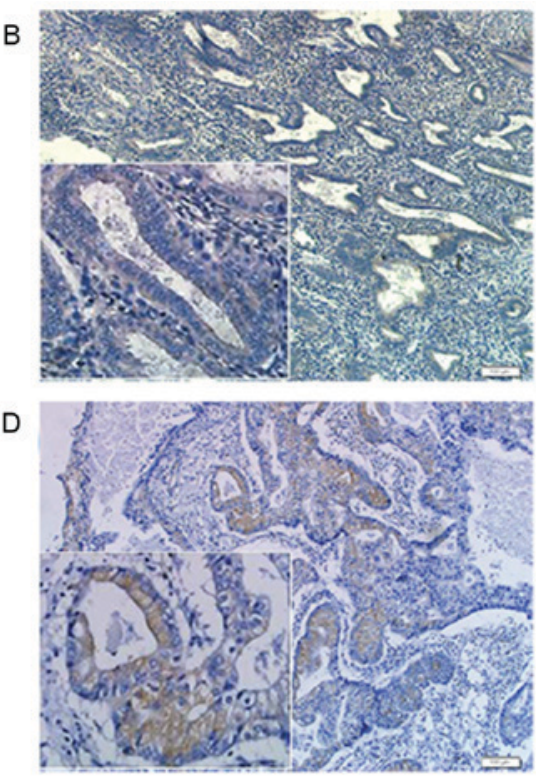

$\mathrm{F}$

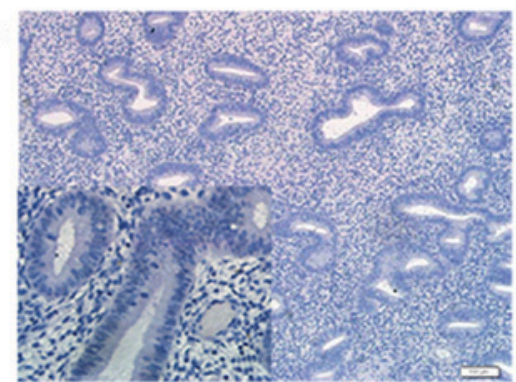

Figure 3. Representative images of immunohistochemical analysis of PDCD4 in the EEC and control groups (x100 magnification and x400 magnification; scale bars $=200 \mu \mathrm{m}$ ). (A) Immunohistochemical staining of PDCD4 in the proliferative phase of control endometrium. (B) Immunohistochemical staining of PDCD4 in the secretory phase of control endometrium. (C) Immunohistochemical staining of PDCD4 in G1 EEC tissues. (D) Immunohistochemical staining of PDCD4 in G2 EEC tissues. (E) Immunohistochemical staining of PDCD4 in G3 EEC tissues. (F) Negative control. PDCD4, programmed cell death 4; EEC, endometrioid endometrial carcinomas.

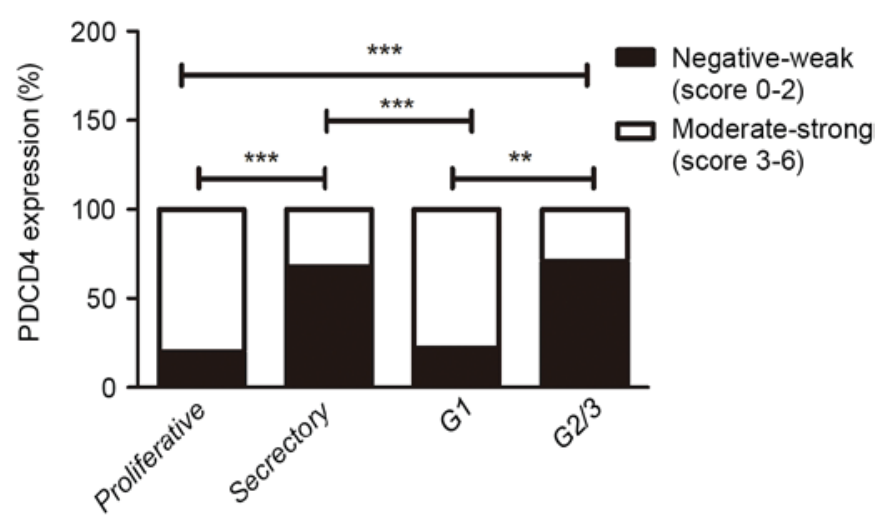

Figure 4. Statistical analysis of PDCD4 expression in 52 EEC tissues and 70 control endometrial tissues. In the control group, the staining index of PDCD4 in the proliferative phase $(n=36)$ was significantly increased compared with that in the secretory phase $(n=34)$. The immunostaining of PDCD4 in G2/3 EEC tissues was lower than that in the proliferative phase of control endometrium. Compared with G1 EEC tissues, PDCD4 expression was downregulated in G2/3 EEC tissues or the secretory phase of contro endometrium. ${ }^{* *} \mathrm{P}<0.01,{ }^{* * *} \mathrm{P}<0.001$ vs. control. $\mathrm{PDCD} 4$, programmed cell death 4; EEC, endometrioid endometrial carcinomas.

control endometrium and G1 EEC tissues, as well as between the secretory phase of control endometrium and G2/3 EEC tissues (Fig. 4). These results suggested that the expression of
PDCD4 could vary in a cyclic fashion in control endometrium and PDCD4 protein was downregulated in the G2/3 EEC tissues.

Expression of PDCD4 protein in control glandular epithelial cells and KLE cells detected by ICC staining. To verify the location of the PDCD4 protein and differences in PDCD4 expression between the control glandular epithelial cells and endometrial carcinomas cells, endometrial glandular epithelial cells and stromal cells were isolated and cultured. As shown in Fig. 5A and B, glandular epithelial cells and stromal cells were respectively characterized by ICC with mouse anti-human cytokeratin and vimentin antibodies. In addition, the results from PDCD4 staining showed that PDCD4 immunostaining in control glandular epithelial and KLE cells was mostly localized in the cytoplasm (Fig. 5C and D). KLE cells exhibited weak PDCD4 staining, which was similar to the secretory phase of control endometrial glandular epithelial cells.

Association analysis between PDCD4 expression in EEC samples and clinicopathological parameters of patients. The association between PDCD4 protein expression detected by IHC and clinicopathological parameters was analyzed. No significant associations were observed between PDCD4 expression and age, the depth of myometrial invasion, FIGO 
A

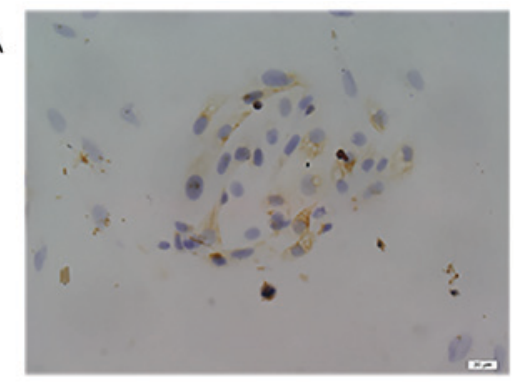

C

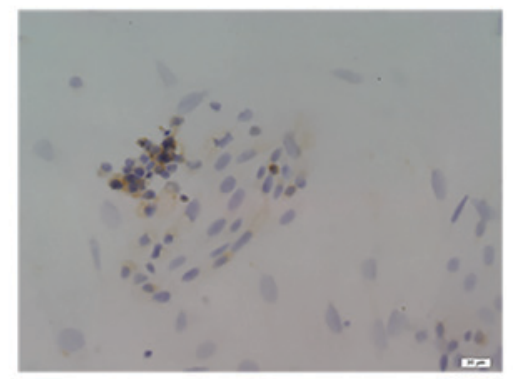

B

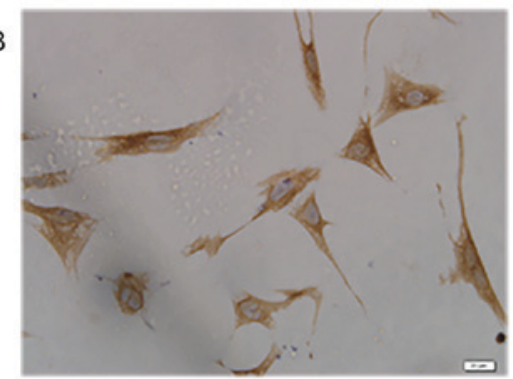

D

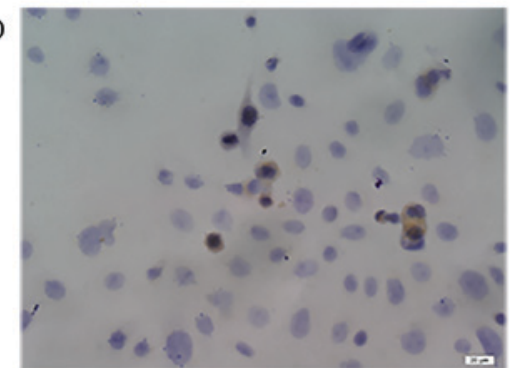

Figure 5. Representative images of immunocytochemical analysis of PDCD4 in control endometrial glandular epithelial cells and KLE cells (x400 magnification; scale bars $=20 \mu \mathrm{m}$ ). (A) Immunocytochemical staining of cytokeratin in the glandular epithelial cells of control endometrium. (B) Immunocytochemical staining of vimentin in the stromal cells of control endometrium. (C) Immunocytochemical staining of PDCD4 in the glandular epithelial cells of control endometrium. (D) Immunocytochemical staining of PDCD4 in KLE cells. PDCD4, programmed cell death 4.

stage, ER or PR. However, PDCD4 expression was significantly associated with the tumor grade; the PDCD4 level in G1 EEC tissues was higher than that in the G2/3 EEC group $(\mathrm{P}<0.01$; Fig. 4; Table I), which suggests that PDCD4 expression may be associated with the malignant progression of patients with EEC.

\section{Discussion}

In the majority of human cancers, including colorectal (25), gastric (26), glioma and ovarian cancers $(18,27)$, PDCD4 mRNA and protein expression is lost or reduced compared with normal tissues. However, in lung squamous cell carcinoma samples, PDCD4 protein and mRNA level alterations do not correlate; the mRNA is low but the protein is unchanged or even upregulated (28). In addition, PDCD4 protein was also found to be highly expressed in bladder and breast carcinoma compared with the corresponding normal tissues $(17,29)$. These data demonstrated that PDCD4 expression levels are varied in different tissues, which indicates that PDCD4 has tissue-specific roles. In the present study, it was observed that PDCD4 protein expression in EEC tissues remain the same as the control. The expression of PDCD4 mRNA in EEC samples was slightly increased compared with the control group, however no significant difference was observed. Torres et al (30) evaluated the expression of PDCD4 in 20 endometrial cancer and 10 normal endometrium samples by qPCR, and the results showed that there were no significant differences in the mRNA expression level of PDCD4 between endometrial cancer and control groups. However, due to the small number of fresh frozen samples, whether the expression of PDCD4 mRNA and protein in EEC tissues was similar to that in the control endometrium remains unclear.

In the present study, 70 formalin-fixed, paraffin-embedded control specimens (including 36 proliferative and 34 secretary phase of endometrium) and 52 EEC samples were collected. The expression of PDCD4 in normal endometrium was detected by IHC, and the staining index of PDCD4 in the proliferative phase was found to be significantly higher than that in the secretory phase, which suggests the expression of PDCD4 could vary in a cyclic fashion. It has been reported that the expression of some certain proteins is different in the proliferative phase or the secretory phase of normal endometrium (31,32). Chen et al (31) found that the staining index of epithelial Musashi-1 in the proliferative phase endometrium was significantly increased compared with the secretory phase endometrium. In addition, COX-2 expression suffers variations during the menstrual cycle in response to the fluctuating levels of estrogen and progesterone in the normal cycling endometrium (32). Estrogen was found to be a potent stimuli of COX-2 expression, whereas progesterone may have the opposite effect, diminishing the expression of COX-2 in the glandular epithelium during the secretory phase $(32,33)$. These data suggested that the expression of PDCD4 may also be affected by the fluctuating levels of estrogen and progesterone.

The expression status of PDCD4 in EEC tissues was investigated by IHC, and the association between PDCD4 expression and clinicopathological parameters was analyzed. The present results indicated PDCD4 expression in G2/3 EEC was decreased compared with the proliferative phase of control endometrium. However, no marked difference was observed between G2/3 EEC and the secretory phase control endometrium. ICC results also confirmed that PDCD4 staining in the KLE cells (high grade endometrial adenocarcinoma cells) expressed similar weak PDCD4 protein compared with the secretory phase of control endometrial glandular epithelial cells. A $\chi^{2}$ test showed that the level of PDCD4 had no significant association with age, the depth of myometrial invasion, tumor stage, ER and PR, while PDCD4 expression was associated with the histological grade of tumor. The level of PDCD4 
in G1 EEC group was higher compared with G2/3 EEC group. Similarly, in ovarian cancer (34), renal cell cancer (13) and pancreatic cancer (35), PDCD4 expression was significantly decreased in G2/3 cancers compared with the G1 cancers. However, Gao et al found that the loss of PDCD4 in gliomas had no significant association with tumor grade or histological type (27). Therefore, in certain types of cancer, including EEC, PDCD4 expression decreases with the decline of differentiation degree, which suggests downregulation of PDCD4 may serve an important role in de-differentiation and progression of certain cancers, and PDCD4 may be an indicator of tumor grade in specific cancers. In addition, PDCD4 protein expression in the proliferative phase of control endometrium and G1 EEC tissues was increased compared with the secretory phase of control endometrium and G2/3 EEC samples, which may be why no significant difference was observed between control endometrium and EEC tissues detected by RT-qPCR and western blotting.

To confirm the subcellular localization of PDCD4, PDCD4 expression sites were observed in control endometrial glandular epithelial and EEC cells detected by IHC and ICC. Notably, PDCD4 positive staining mainly existed in the cytoplasm of these cells, while no evident staining was observed in the nucleus. The present results are consistent with the study by Zhang et al (36), which identified that PDCD4 protein was localized in the cytoplasm of adjacent non-cancerous hepatocytes and hepatocellular carcinoma cells. However, Chen et al (15) reported that PDCD4 staining was localized in the nuclei and cytoplasm of lung cancer cells. These discrepancies may be due to the fact that PDCD4 could shuttle between nucleus and cytoplasm (37). It has been reported that a nuclear translocation of PDCD4 is controlled by protein kinase B/Akt-mediated PDCD4 phosphorylation at Ser67 and Ser457 (38). Another explanation for different subcellular localization may be a cell-type specific action of PDCD4.

In conclusion, the present study demonstrated that PDCD4 protein expression was downregulated in G2/3 EEC compared with the proliferative phase of normal endometrium and G1 of EEC. These results indicated that PDCD4 serves an important role in determining the tumor grade of EEC. With respect to these findings, PDCD4 may be a valuable indicator of the degree of tumor malignancy in patients with EEC.

\section{Acknowledgements}

Not applicable.

\section{Funding}

The present study was supported by the National 973 Basic Research Program of China (grant no. 2011CB503906), the National Natural Science Foundation of China (grant nos. 81471437 and 31470856) and the Natural Science Foundation of Shandong (grant nos. ZR2012HM091 and ZR2013HM105).

\section{Availability of data and materials}

The datasets generated during the present study are available upon reasonable request from the corresponding author.

\section{Author's contributions}

ZW designed the project and conducted the experimental study. XW made substantial contributions to experimental design and implementation, drafted the manuscript and revised it critically for intellectual content. YanL collected the samples, performed the experiments and wrote the manuscript. HS participated in designing the experiments, drafting and revising the manuscript. HM collected the samples. MG and XT were involved in performing experiments. YuL and YaL were involved in data collection and statistical analysis. GMM and LZ were involved in made substantial contributions to analysis and interpretation of data. All authors read and approved the final manuscript.

\section{Ethics approval and consent to participate}

All the subjects included in the study signed informed consents. The Institutional Ethics Committee of Shandong University approved the present study.

\section{Consent for publication}

The patients provided written informed consent for the publication of the present study.

\section{Competing interests}

The authors declare that they have no competing interests.

\section{References}

1. Shevra CR, Ghosh A and Kumar M: Cyclin D1 and Ki-67 expression in normal, hyperplastic and neoplastic endometrium. J Postgrad Med 61: 15-20, 2015.

2. Bokhman JV: Two pathogenetic types of endometrial carcinoma. Gynecol Oncol 15: 10-17, 1983.

3. Llauradó M, Ruiz A, Majem B, Ertekin T, Colás E, Pedrola N, Devis L, Rigau M, Sequeiros T, Montes M, et al: Molecular bases of endometrial cancer: New roles for new actors in the diagnosis and the therapy of the disease. Mol Cell Endocrinol 358: 244-255, 2012.

4. Shibahara K, Asano M, Ishida Y, Aoki T, Koike T and Honjo T: Isolation of a novel mouse gene MA-3 that is induced upon programmed cell death. Gene 166: 297-301, 1995.

5. Jansen AP, Camalier CE and Colburn NH: Epidermal expression of the translation inhibitor programmed cell death 4 suppresses tumorigenesis. Cancer Res 65: 6034-6041, 2005.

6. Allgayer H: Pdcd4, a colon cancer prognostic that is regulated by a microRNA. Crit Rev Oncol Hematol 73: 185-191, 2010.

7. Bitomsky N, Böhm M and Klempnauer KH: Transformation suppressor protein Pdcd4 interferes with JNK-mediated phosphorylation of c-Jun and recruitment of the coactivator p300 by c-Jun. Oncogene 23: 7484-7493, 2004.

8. Leupold JH, Yang HS, Colburn NH, Asangani I, Post S and Allgayer H: Tumor suppressor Pdcd4 inhibits invasion/intravasation and regulates urokinase receptor (u-PAR) gene expression via Sp-transcription factors. Oncogene 26: 4550-4562, 2007.

9. Wedeken L, Singh P and Klempnauer KH: Tumor suppressor protein Pded 4 inhibits translation of p53 mRNA. J Biol Chem 286: 42855-42862, 2011.

10. Yang HS, Jansen AP, Komar AA, Zheng X, Merrick WC, Costes S, Lockett SJ, Sonenberg N and Colburn NH: The transformation suppressor Pdcd4 is a novel eukaryotic translation initiation factor $4 \mathrm{~A}$ binding protein that inhibits translation. Mol Cell Biol 23: 26-37, 2003.

11. Fehler O, Singh P, Haas A, Ulrich D, Müller JP, Ohnheiser J and Klempnauer KH: An evolutionarily conserved interaction of tumor suppressor protein Pdcd4 with the poly(A)-binding protein contributes to translation suppression by Pdcd4. Nucleic Acids Res 42: 11107-11118, 2014. 
12. Zhang H, Ozaki I, Mizuta T, Hamajima H, Yasutake T, Eguchi Y, Ideguchi H, Yamamoto $\mathrm{K}$ and Matsuhashi S: Involvement of programmed cell death 4 in transforming growth factor-beta1-induced apoptosis in human hepatocellular carcinoma. Oncogene 25: 6101-6112, 2006.

13. Li X, Xin S, Yang D, Li X, He Z, Che X, Wang J, Chen F, Wang X and Song X: Down-regulation of PDCD4 expression is an independent predictor of poor prognosis in human renal cell carcinoma patients. J Cancer Res Clin Oncol 138: 529-535, 2012.

14. Gao F, Wang X, Zhu F, Wang Q, Zhang X, Guo C, Zhou C, Ma C, Sun W, Zhang Y, et al: PDCD4 gene silencing in gliomas is associated with $5^{\prime} \mathrm{CpG}$ island methylation and unfavourable prognosis. J Cell Mol Med 13: 4257-4267, 2009.

15. Chen Y, Knösel T, Kristiansen G, Pietas A, Garber ME, Matsuhashi S, Ozaki I and Petersen I: Loss of PDCD4 expression in human lung cancer correlates with tumour progression and prognosis. J Pathol 200: 640-646, 2003.

16. Mudduluru G, Medved F, Grobholz R, Jost C, Gruber A, Leupold JH, Post S, Jansen A, Colburn NH and Allgayer H: Loss of programmed cell death 4 expression marks adenoma-carcinoma transition, correlates inversely with phosphorylated protein kinase $\mathrm{B}$, and is an independent prognostic factor in resected colorectal cancer. Cancer 110: 1697-1707, 2007.

17. Afonja O, Juste D, Das S, Matsuhashi S and Samuels HH: Induction of PDCD4 tumor suppressor gene expression by RAR agonists, antiestrogen and HER-2/neu antagonist in breast cancer cells. Evidence for a role in apoptosis. Oncogene 23: 8135-8145, 2004.

18. Wei ZT, Zhang X, Wang XY, Gao F, Zhou CJ, Zhu FL, Wang Q, Gao Q, Ma CH, Sun WS, et al: PDCD4 inhibits the malignant phenotype of ovarian cancer cells. Cancer Sci 100: 1408-1413, 2009.

19. Yang T, Qiu H, Bao W, Li B, Lu C, Du G, Luo X, Wang L and Wan X: Epigenetic inactivation of EFEMP1 is associated with tumor suppressive function in endometrial carcinoma. PLoS One 8: e67458, 2013.

20. Walentowicz-Sadlecka M, Sadlecki P, Bodnar M, Marszalek A, Walentowicz P, Sokup A, Wilińska-Jankowska A and Grabiec M: Stromal derived factor-1 (SDF-1) and its receptors CXCR4 and CXCR7 in endometrial cancer patients. PLoS One 9: e84629, 2014.

21. Jeon YT, Park IA, Kim YB, Kim JW, Park NH, Kang SB, Lee HP and Song YS: Steroid receptor expressions in endometrial cancer: Clinical significance and epidemiological implication. Cancer Lett 239: 198-204, 2006.

22. Livak KJ and Schmittgen TD: Analysis of relative gene expression data using real-time quantitative PCR and the 2(-Delta Delta C(T)) method. Methods 25: 402-408, 2001.

23. Remmele W and Stegner HE: Recommendation for uniform definition of an immunoreactive score (IRS) for immunohistochemical estrogen receptor detection (ER-ICA) in breast cancer tissue. Pathologe 8: 138-140, 1987 (In German).

24. Zhang H,LiM,Zheng X, Sun Y, WenZ andZhao X: Endometriotic stromal cells lose the ability to regulate cell-survival signaling in endometrial epithelial cells in vitro. Mol Hum Reprod 15: 653-663, 2009.
25. Chang KH, Miller N, Kheirelseid EA, Ingoldsby H, Hennessy E, Curran CE, Curran S, Smith MJ, Regan M, McAnena OJ and Kerin MJ: MicroRNA-21 and PDCD4 expression in colorectal cancer. Eur J Surg Oncol 37: 597-603, 2011

26. Gu W, Gao T, Shen J, Sun Y, Zheng X, Wang J, Ma J, Hu XY, Li J and Hu MJ: MicroRNA-183 inhibits apoptosis and promotes proliferation and invasion of gastric cancer cells by targeting PDCD4. Int J Clin Exp Med 7: 2519-2529, 2014.

27. Gao F, Zhang P, Zhou C, Li J, Wang Q, Zhu F, Ma C, Sun W and Zhang L: Frequent loss of PDCD4 expression in human glioma: Possible role in the tumorigenesis of glioma. Oncol Rep 17: 123-128, 2007.

28. Kalinichenko SV, Kopantzev EP, Korobko EV, Palgova IV, Zavalishina LE, Bateva MV, Petrov AN, Frank GA, Sverdlov ED and Korobko IV: Pdcd4 protein and mRNA level alterations do not correlate in human lung tumors. Lung Cancer 62: 173-180, 2008.

29. Lei Y, Hu X, Li B, Peng M, Tong S, Zu X, Wang Z, Qi L and Chen M: miR-150 modulates cisplatin chemosensitivity and invasiveness of muscle-invasive bladder cancer cells via targeting PDCD4 in vitro. Med Sci Monit 20: 1850-1857, 2014.

30. Torres A, Torres K, Paszkowski T, Radej S, Staśkiewicz GJ, Ceccaroni M, Pesci A and Maciejewski R: Highly increased maspin expression corresponds with up-regulation of miR-21 in endometrial cancer: A preliminary report. Int J Gynecol Cancer 21: 8-14, 2011.

31. Chen YZ, Wang JH, Yan J, Liang Y, Zhang XF and Zhou F: Increased expression of the adult stem cell marker Musashi-1 in the ectopic endometrium of adenomyosis does not correlate with serum estradiol and progesterone levels. Eur J Obstet Gynecol Reprod Biol 173: 88-93, 2014.

32. Maia H Jr, Maltez A, Studard E, Zausner B, Athayde C and Coutinho E: Effect of the menstrual cycle and oral contraceptives on cyclooxygenase-2 expression in the endometrium. Gynecol Endocrinol 21: 57-61, 2005.

33. Bulun SE, Zeitoun KM, Takayama K and Sasano H: Molecular basis for treating endometriosis with aromatase inhibitors. Hum Reprod Update 6: 413-418, 2000.

34. Wang X, Wei Z, Gao F, Zhang X, Zhou C, Zhu F, Wang Q, Gao Q, Ma C, Sun W, et al: Expression and prognostic significance of PDCD4 in human epithelial ovarian carcinoma. Anticancer Res 28: 2991-2996, 2008.

35. Ma G, Zhang H, Dong M, Zheng X, Ozaki I, Matsuhashi S and Guo K: Downregulation of programmed cell death 4 (PDCD4) in tumorigenesis and progression of human digestive tract cancers. Tumour Biol 34: 3879-3885, 2013.

36. Zhang S, Li J, Jiang Y, Xu Y and Qin C: Programmed cell death 4 (PDCD4) suppresses metastastic potential of human hepatocellular carcinoma cells. J Exp Clin Cancer Res 28: 71, 2009.

37. Böhm M, Sawicka K, Siebrasse JP, Brehmer-Fastnacht A, Peters R and Klempnauer KH: The transformation suppressor protein Pdcd4 shuttles between nucleus and cytoplasm and binds RNA. Oncogene 22: 4905-4910, 2003.

38. Palamarchuk A, Efanov A, Maximov V, Aqeilan RI, Croce CM and Pekarsky Y: Akt phosphorylates and regulates Pdcd4 tumor suppressor protein. Cancer Res 65: 11282-11286, 2005. 